\title{
User Preferences for Mobile Health Interventions: A Survey among Intermittent Claudication Patients and Their Physical Therapists
}

Citation for published version (APA):

van den Houten, M. M. L., Spruijt, S., Fokkenrood, H. J. P., Scheltinga, M. R. M., \& Teijink, J. A. W. (2018). User Preferences for Mobile Health Interventions: A Survey among Intermittent Claudication Patients and Their Physical Therapists. Annals of Vascular Surgery, 46, 249-256.

https://doi.org/10.1016/j.avsg.2017.08.020

Document status and date:

Published: 01/01/2018

DOI:

10.1016/j.avsg.2017.08.020

Document Version:

Publisher's PDF, also known as Version of record

Document license:

Taverne

Please check the document version of this publication:

- A submitted manuscript is the version of the article upon submission and before peer-review. There can be important differences between the submitted version and the official published version of record.

People interested in the research are advised to contact the author for the final version of the publication, or visit the DOI to the publisher's website.

- The final author version and the galley proof are versions of the publication after peer review.

- The final published version features the final layout of the paper including the volume, issue and page numbers.

Link to publication

\footnotetext{
General rights rights.

- You may freely distribute the URL identifying the publication in the public portal. please follow below link for the End User Agreement:

www.umlib.nl/taverne-license

Take down policy

If you believe that this document breaches copyright please contact us at:

repository@maastrichtuniversity.nl

providing details and we will investigate your claim.
}

Copyright and moral rights for the publications made accessible in the public portal are retained by the authors and/or other copyright owners and it is a condition of accessing publications that users recognise and abide by the legal requirements associated with these

- Users may download and print one copy of any publication from the public portal for the purpose of private study or research.

- You may not further distribute the material or use it for any profit-making activity or commercial gain

If the publication is distributed under the terms of Article 25fa of the Dutch Copyright Act, indicated by the "Taverne" license above, 


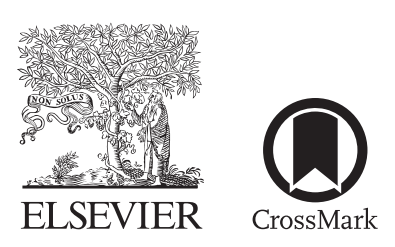

\title{
User Preferences for Mobile Health Interventions: A Survey among Intermittent Claudication Patients and Their Physical Therapists
}

\author{
Marijn M.L. van den Houten, ${ }^{1,2}$ Steffie Spruijt, ${ }^{3}$ Hugo J.P. Fokkenrood, ${ }^{4}$ \\ Marc R.M. Scheltinga, and Joep A.W. Teijink, ${ }^{1,2}$ Eindhoven, Maastricht, Arnhem, and \\ Veldhoven, The Netherlands
}

\begin{abstract}
Background: Smartphone apps provide novel ways for triggering lifestyle change by coupling objective measurements of health behavior with tailored feedback. Little is known about enduser preferences regarding the content of mobile health (mHealth) interventions. The aim of this study was to assess smartphone use and preferences regarding app content among intermittent claudication patients and their treating physical therapists.

Methods: A cross-sectional survey was sent via an internal email system to 1,514 physical therapists specialized in treating patients with intermittent claudication. They were asked to complete one questionnaire themselves and administer a second to their intermittent claudication patients currently under treatment. Data on participant characteristics and smartphone use were collected from all respondents. The preferred app components were obtained from participants owning a smartphone. Binary logistic regression analysis was used to explore the adjusted association between age and attained educational level, and smartphone use.

Results: The response rate of therapists was $40.8 \%(617 / 1,514)$, and a total of 488 patients completed the survey. After excluding incomplete forms, a total of 615 physical therapist forms and 483 patient forms were analyzed. Overall, $40.6 \%$ of patients and $95 \%$ of therapists owned a smartphone. Higher educational level was associated with smartphone ownership (adjusted odds ratio $=2.46,95 \%$ confidence interval $(\mathrm{Cl})=1.41-4.27, P=0.001)$. Compared to patients aged $\geq 75$ years, lower age was associated with higher odds of owning a smartphone (adjusted odds ratios for patients aged $\leq 54$ years $=21.27,95 \% \mathrm{Cl}=6.82-66.30, P<0.001$; aged $55-64$ years $=4.76,95 \% \mathrm{Cl}=2.52-9.00, P<0.001$; and aged $65-74$ years $=2.58,95 \%$ $\mathrm{Cl}=1.54-4.33, P<0.001)$. The most preferred app components for intermittent claudication patients in possession of a smartphone included monitoring treadmill-measured walking distances $(71 \%)$, global positioning system tracking of walks $(50 \%)$, and daily physical activity monitoring (49\%). Physical therapists were most interested in global positioning system tracking of walks $(89 \%)$, daily physical activity monitoring $(82 \%)$, keeping track of treadmill-measured walking distance $(79 \%)$, help with smoking cessation $(65 \%)$.
\end{abstract}

The authors have no conflicts of interest to disclose.

This research did not receive any specific grant from funding agencies in the public, commercial, or not-for-profit sectors.

${ }^{I}$ Department of Surgery, Catharina Hospital, Eindhoven, The Netherlands.

${ }^{2}$ Care and Public Health Research Institute (CAPHRI), Maastricht University Medical Centre, Maastricht, The Netherlands.

${ }^{3}$ ClaudicatioNet, Eindhoven, The Netherlands.

${ }^{4}$ Department of Surgery, Rijnstate Hospital, Arnhem, The Netherlands.
${ }^{5}$ Department of Surgery, Maxima Medical Center, Veldhoven, The Netherlands.

Correspondence to: Joep A.W. Teijink, MD, PhD, Department of Vascular Surgery, Catharina Hospital, Michelangelolaan 2, P.O. Box 1350, Eindhoven 5623 EJ, The Netherlands; E-mail: joep.teijink@cze.nl

Ann Vasc Surg 2018; 46: 249-256 https://doi.org/10.1016/j.avsg.2017.08.020

(C) 2017 Elsevier Inc. All rights reserved.

Manuscript received: May 31, 2017; manuscript accepted: August 1, 2017; published online: 8 September 2017 


\begin{abstract}
Conclusions: Smartphone ownership is associated with younger age and a higher educational level in patients with intermittent claudication. This study provides a framework of end-user preferences regarding desired features to guide the development of an app to potentiate health outcomes of intermittent claudication treatment.
\end{abstract}

\section{INTRODUCTION}

Peripheral arterial disease (PAD) of the lower extremities is a chronic disease caused by atherosclerosis and afflicts over 200 million people worldwide. ${ }^{1}$ Intermittent claudication (IC) is the most common symptomatic manifestation of lower extremity PAD. Current guidelines advise supervised exercise therapy (SET) as a primary treatment for IC. ${ }^{2}$ Through SET sessions, consisting of walking to near-maximum pain, IC patients gradually increase walking function and thereby quality of life. $^{3}$ Additionally, treatment guidelines focus on secondary prevention methods modifying known risk factors of cardiovascular complications or death; smoking cessation, improvement of daily life physical activity, and the adoption of a healthy diet. ${ }^{2}$

In the Netherlands, SET is provided by specialized physical therapists (PTs) who offer both symptomatic treatment as well as facilitation of improvement of lifestyle factors through the use of motivational interviewing techniques. However, these face-toface clinical consultations alone may be insufficient to convey the amount of information and support that is necessary to counsel and motivate patients to achieve a durable change in behavior. ${ }^{4}$ The emergence of new information and communication technology provides novel ways of delivering health care; termed "eHealth." " Mobile health (mHealth), a segment of eHealth, represents the use of mobile computing and communication technologies such as mobile phones in health care. ${ }^{4}$ Modern smartphones provide Internet access, video, audio, social media and can utilize built-in or wearable measurement devices such as accelerometers or global positioning systems (GPSs), aggregating data on a patient's health behavior, including daily physical activity. Collection and subsequent incorporation of these data in modern mHealth solutions permits the provision of interactive interventions, individualized to the specific patient's individual characteristics and context. Furthermore, with objective information on patients' daily health behavior PTs can better tailor lifestyle counseling and SET sessions.

Smartphone applications, or "apps", have a potential to induce a meaningful change in health behavior. Unsurprisingly, apps aimed at improving self-management and health promotion are becoming increasingly popular. Yet, while a multitude of health-related smartphone apps are commercially available, most lack an evidence and theory base, ${ }^{4}$ whereas neither clinicians nor patients were involved in their development. ${ }^{6}$ Furthermore, the target audience is relatively young and healthy. To our knowledge, smartphone penetration and app use in the PAD or IC population have never been assessed, while the general characteristics of PAD patients (older age, limited educational attainment, and high cardiovascular risk) are associated with lower digital connectedness. ${ }^{7}$ Thereby it is unknown whether smartphone apps have sufficient reach in this patient category. It is important to involve the end users in the design process of a smartphone application in health care to better match the patient's needs and expectations and potentiate effectiveness. ${ }^{8,9}$ Developers will benefit from information on patient and PT preferences regarding desired app features for specific patient populations.

The goal of this study was to assess the feasibility of mHealth for patients with PAD by determining smartphone and app usage in the IC population in the Netherlands. Furthermore, we aimed to assess preferences regarding app content of both IC patients and PTs. The results of the study will provide a publicly accessible framework to aid in the development of future mHealth lifestyle interventions.

\section{MATERIAL AND METHODS}

\section{Design, Setting, and Participants}

The smartphone penetration among IC patients and PTs, as well as preferred app components were assessed by collecting quantitative data using 2 questionnaires in a cross-sectional, closed survey. Eligible participants were IC patients currently under SET treatment and PTs affiliated with ClaudicatioNet. This is a Dutch network of PTs specialized in SET and was chosen to ensure a nation-wide reach of the survey with the possibility of quickly establishing a large sample size. ClaudicatioNet guarantees quality of care through mandatory training courses in practice guidelines, ${ }^{10}$ motivational interviewing skills, and a minimum of $15 \mathrm{hr}$ per year in other IC-relevant topics. ${ }^{11}$ Owing to these schooling 
requirements, paired with a quality monitoring system using automated data extraction from electronic health records, ClaudicatioNet PTs offer a standardized SET program. This typically entails 3 months of 2-3 weekly, 30-min, sessions of supervised (treadmill) exercise and lifestyle counseling, In the following months, treatment frequency gradually drops as a means to promote self-management leading to a self-reliant patient. Standardization and contents of conservative IC treatment in the Netherlands have been described in more detail elsewhere. $^{12}$

Two online questionnaires were sent to a closed population of 1,514 PTs throughout the Netherlands. By using an integral email system, it was guaranteed that only certified ClaudicatioNet therapists received the questionnaire. They were subsequently invited to complete one version of the survey themselves and administer a similar second copy to all their patients receiving SET for IC in the following 4 weeks. This study design was chosen to maximize the number of exposed IC patients and therapists throughout the Netherlands, including patients referred by general practitioners. The survey was voluntary for both patients and PTs, and no incentives were offered to participants. Responses, collected between November 10, 2015 and December 11, 2015, were anonymous without identifiable data. The study was approved by the Medical Ethical Committee of the Catharina Hospital.

\section{Questionnaire}

The survey was an online, web-based questionnaire, assembled with Google Forms (Google Inc., Mountain View, CA). The design of the questionnaire was largely based on the results of a systematic review and scientific statement by Burke et al. ${ }^{4} \mathrm{~A}$ primordial version was discussed and adapted by a team consisting of a vascular surgeon, a PT, and 2 vascular surgery $\mathrm{PhD}$ candidates (medical doctors). The improved version was pilot tested in the same team to adjust for any errors. The final patient questionnaire included 4 pages with a total of 8 questions (in Dutch). The first questions determined sociodemographic information (age, gender, and highest educational level). Subsequently, mobile phone and smartphone ownership were established. The remainder of the patient questionnaire was conditionally displayed based on whether participants owned a smartphone. Two questions inquired about the smartphone operating system and number of lifetime app downloads of patients. Finally, participants were asked to indicate which components of a potential smartphone app they found interesting in a closed question with multiple answers including an open "other" option. The components were formulated based on the scientific statement from the American Heart Association ${ }^{4}$ and through discussion by the research team and ClaudicatioNet management. The display order of answers to this final question was randomized to prevent bias. The PT questionnaire was similar, except the "highest educational level question" was excluded. An English translation of the survey is available in Appendix 1 in the supplementary material.

Respondents were able to modify their answers throughout the questionnaire, made possible by a "back" button. A printable version of the patient questionnaire was available for therapists if preferred.

\section{Statistical Analysis}

The online survey was administered through Google Forms (Google Inc., Mountain View, CA). Results were analyzed using SPSS version 22.0 (IBM Inc., Armonk, NY). Data were screened to ensure that all forms were completed correctly. When this was not the case (i.e., incomplete response on key elements), the questionnaire was excluded from analysis. Categorical variables were expressed as numbers with percentages and continuous variables as means with standard deviation (SD). Pearson's chi-squared test was used to detect differences between proportions, applying a statistical significance level of $P<0.05$. Binary logistic regression analysis, using the enter method, was used to explore the adjusted association between age, gender, and attained educational level, and smartphone use. A $P$ value of $<0.2$ was used in univariable analysis to select variables for multivariable analysis. The results were expressed as odds ratios with corresponding $95 \%$ confidence intervals. Results were presented according to the Checklist for Reporting Results of Internet E-Surveys ${ }^{13}$ and a similar checklist for reporting survey research formulated by Bennett et al. ${ }^{14}$

\section{RESULTS}

\section{Overview}

Of 1,514 PTs that were contacted, 617 completed the web survey ( $40.8 \%$ response rate). Data from a total of 488 IC patients receiving treatment at that time were collected via their PTs. Two $(0.03 \%)$ therapist forms and $5(0.1 \%)$ patient forms were excluded due to incomplete responses on smartphone 
Table I. Characteristics and smartphone ownership of patients with IC $(n=483)$ and their PTs $(n=615)$

\begin{tabular}{lc}
\hline Characteristics & \multicolumn{1}{l}{ Value } \\
\hline Patients & \\
Age, y, mean (SD) & $69.9(9.4)(n=469)$ \\
Gender, $n$ male (\%) & $271(56.5)(n=480)$ \\
Educational attainment, $n(\%)$ & \\
$\quad(n=480)$ & $4(0.8)$ \\
$\quad$ None & $47(9.8)$ \\
$\quad$ Elementary school & $148(30.8)$ \\
$\quad$ Secondary education & $132(27.5)$ \\
$\quad$ Lower vocational education & $65(13.5)$ \\
$\quad$ Intermediate vocational & $67(14)$ \\
$\quad$ education & $17(3.5)$ \\
$\quad$ Higher vocational education & \\
$\quad$ University degree & $413(85.9)(n=481)$ \\
Owns a mobile phone, $n(\%)$ & \\
Owns a smartphone, $n(\%)$ & $196(40.6)$ \\
Physical therapists & $43.7(12.1)(n=607)$ \\
Age, y, mean (SD) & \\
Gender, $n$ male (\%) & \\
Owns a mobile phone, $n(\%)$ & $611(99.3)$ \\
Owns a smartphone, $n(\%)$ & $584(95)$ \\
\hline
\end{tabular}

SD, standard deviation; $n$, number; $y$, years.

${ }^{a}$ The mean age of all ClaudicatioNet therapists is $44 \pm 12$ years where $45 \%$ is male (data based on a total of 1,426 therapists).

ownership, resulting in 615 therapist forms and 483 patient forms eligible for analysis. Participant characteristics are summarized in Table I.

\section{Smartphone Ownership and App Downloads}

Table II shows the results regarding app downloads and smartphone operating systems. Overall, 196 $(40.6 \%)$ patients owned a smartphone, of which $112(57.1 \%)$ downloaded $1-5$ apps and 30 $(15.3 \%)$ downloaded $>5$ apps. In contrast, 54 $(27.6 \%)$ never downloaded an app previously.

With respect to gender, $43.9 \%$ (119/271) of male patients and $35.9 \%(75 / 176)$ of female patients owned a smartphone $(P=0.076)$. Smartphone ownership rates declined with increasing age (Fig. 1). Lower age was associated with higher odds of owning a smartphone, as was a high educational level (higher vocational education or a university degree, Table III). An association between smartphone ownership and gender was not present. Smartphone ownership was common among PTs; $584 / 615(95 \%)$ owned a smartphone, whereas only $14 / 584(2.4 \%)$ had never downloaded an app previously.
Table II. Operating system and app downloads amongst IC patients and PTs owning a smartphone

\begin{tabular}{lrl}
\hline Characteristics & Patients $(n=196)$ & $\begin{array}{l}\text { Physical therapists } \\
(n=584)\end{array}$ \\
\hline \multicolumn{2}{l}{ Smartphone operating system, $n(\%)$} \\
Google Android & $125(63.8)$ & $305(52.2)$ \\
Apple iOS & $56(28.6)$ & $264(45.2)$ \\
Windows Phone & $10(5.1)$ & $10(1.7)$ \\
Other & $5(2.6)$ & $5(0.9)$ \\
App downloads, $n(\%)$ & $14(2.4)$ \\
None & $54(27.6)$ & $108(18.5)$ \\
l-5 & $112(57.1)$ & $462(79.1)$ \\
More than 5 & $30(15.3)$ & \\
\hline
\end{tabular}

\section{User Preferences regarding App Features}

The preferred components of an app of both therapists and patients are presented in Figure 2. The most preferred components for patients in possession of a smartphone included keeping track of treadmill-measured walking distances $(71 \%, 151 /$ 196), GPS tracking of walks $(50 \%, 97 / 196)$, daily physical activity tracking $(49 \%, 95 / 196)$, and education on PAD $(42 \%, 82 / 196)$. Connecting with peers $(6.6 \%, 13 / 196)$ and supporting medication adherence $(8.2 \%, 16 / 196)$ were least preferred amongst PAD patients. Although not a formal survey question, 7 patients $(3.6 \%)$ indicated in the free-text field that they had no interest in any of the suggested features. PTs were mostly interested in GPS tracking of walks $(89 \%, 520 / 584)$, daily physical activity tracking $(82 \%, 481 / 584)$, keeping track of treadmill-measured walking distance (79\%, 460/584), smoking cessation (65\%, 377/ $584)$, and providing information on a healthy lifestyle $(62 \%, 359 / 584)$.

\section{DISCUSSION}

This study investigated the smartphone penetration among end users of mHealth interventions in patients with IC. The results show that $41 \%$ of responding patients with IC owned a smartphone. In general, these owners were younger and had a higher educational level compared to nonowners. The survey responses in this study also provide insight into user preferences regarding potential app features. Both patients and therapists shared an interest in features that facilitate keeping track of walking distance limitations, GPS tracking of walks, and tracking daily physical activity. In general, PTs displayed more interest in app features 


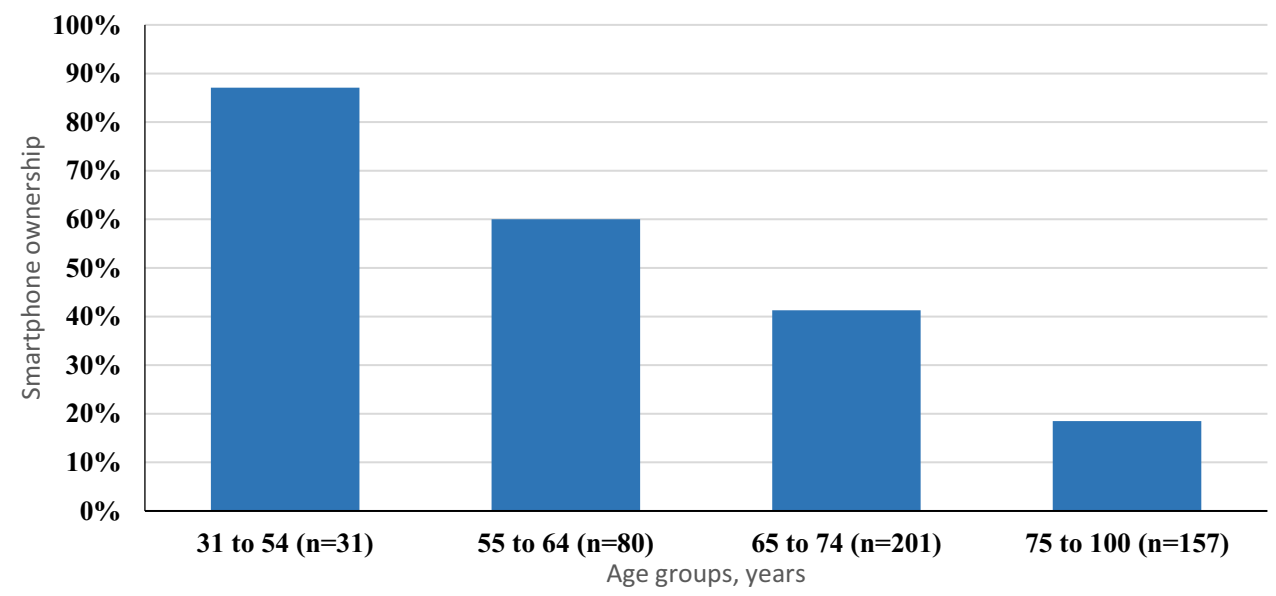

Fig. 1. Smartphone ownership per age category in patients with intermittent claudication $(n=469)$.

Table III. Determinants of smartphone ownership versus nonownership among patients

\begin{tabular}{lcc}
\hline Independent determinant & OR $(95 \% \mathrm{CI})$ & $P$ value \\
\hline $\begin{array}{l}\text { Higher educational } \\
\text { attainment }\end{array}$ & $2.46(1.41-4.27)$ & 0.001 \\
Age categories $^{\mathrm{a}}$ & & \\
$\leq 54$ & $21.27(6.82-66.30)$ & 0.000 \\
$55-64$ & $4.76(2.52-9.00)$ & 0.000 \\
$65-74$ & $2.58(1.54-4.33)$ & 0.000 \\
$\geq 75$ & Reference & \\
\hline
\end{tabular}

CI, confidence interval; OR, odds ratio.

${ }^{\mathrm{a}}$ Indicating higher vocational education or a university degree.

compared to patients. This was especially apparent for patient education, information on a healthy lifestyle, and support with smoking cessation.

Less than half of the IC population owns a smartphone, based on the large sample of patients in the current study. Similar rates have been reported for corresponding age categories in the general population, ${ }^{7}$ although these rates have been rapidly increasing over the past years. ${ }^{15}$ In the present study, smartphone owners were younger and had higher educational attainment compared to nonowners, characteristics that are both known to be inversely associated with cardiovascular risk. Accordingly, Fox et al. ${ }^{7}$ found that digital connectedness was associated with more favorable cardiovascular disease risk profiles. Thus, smartphone-based interventions may predominantly reach PAD subpopulations with a relatively favorable prognosis. ${ }^{16}$ Developers of mHealth interventions should strive to involve patients without access to the appropriate technology, as this particular subgroup may be most in need. Wearable activity trackers have rapidly been gaining popularity in the recent years and may be used in this regard. Furthermore, integration of mHealth with SET programs, performed by PTs trained in motivational interviewing, may provide the necessary guidance for these generally older, less educated, IC patients. Indeed, the deployment of mHealth in tandem with existing in-person counseling efforts has been suggested to potentiate effectiveness. ${ }^{17,18}$ Rates of smartphone ownership and lifetime app downloads among PTs were high, implying their capability of supporting patients in the use of mHealth.

The content preferences regarding potential app features provided by the current survey give developers the means to better tailor their product to the needs of the intended population. Involvement of these end users in the development process is pivotal for achieving user engagement, ${ }^{9}$ which is an important determinant of effectiveness. ${ }^{19}$ Yet, most available medical apps aimed at patients with vascular disease lack medical professional involvement in their design and content. ${ }^{6}$ Previous published research regarding cardiovascular disease patients' or clinicians' preferences on mHealth content is sparse. Rabin and Bock ${ }^{20}$ reported a particular interest in automatic physical activity tracking with feedback on goal accomplishment among sedentary adults. Likewise, PTs and IC patients in the current study regarded features linked to daily physical activity important; including measurement of ambulant activity and tracking walks through GPS. Conway et al. ${ }^{21}$ reported a notable lack of enthusiasm for social media integration in apps amongst diabetes patients. Similarly, participants of the present study showed little interest in the ability to connect with their peers trough mHealth apps. The use of these results, plus the novel insights obtained by 


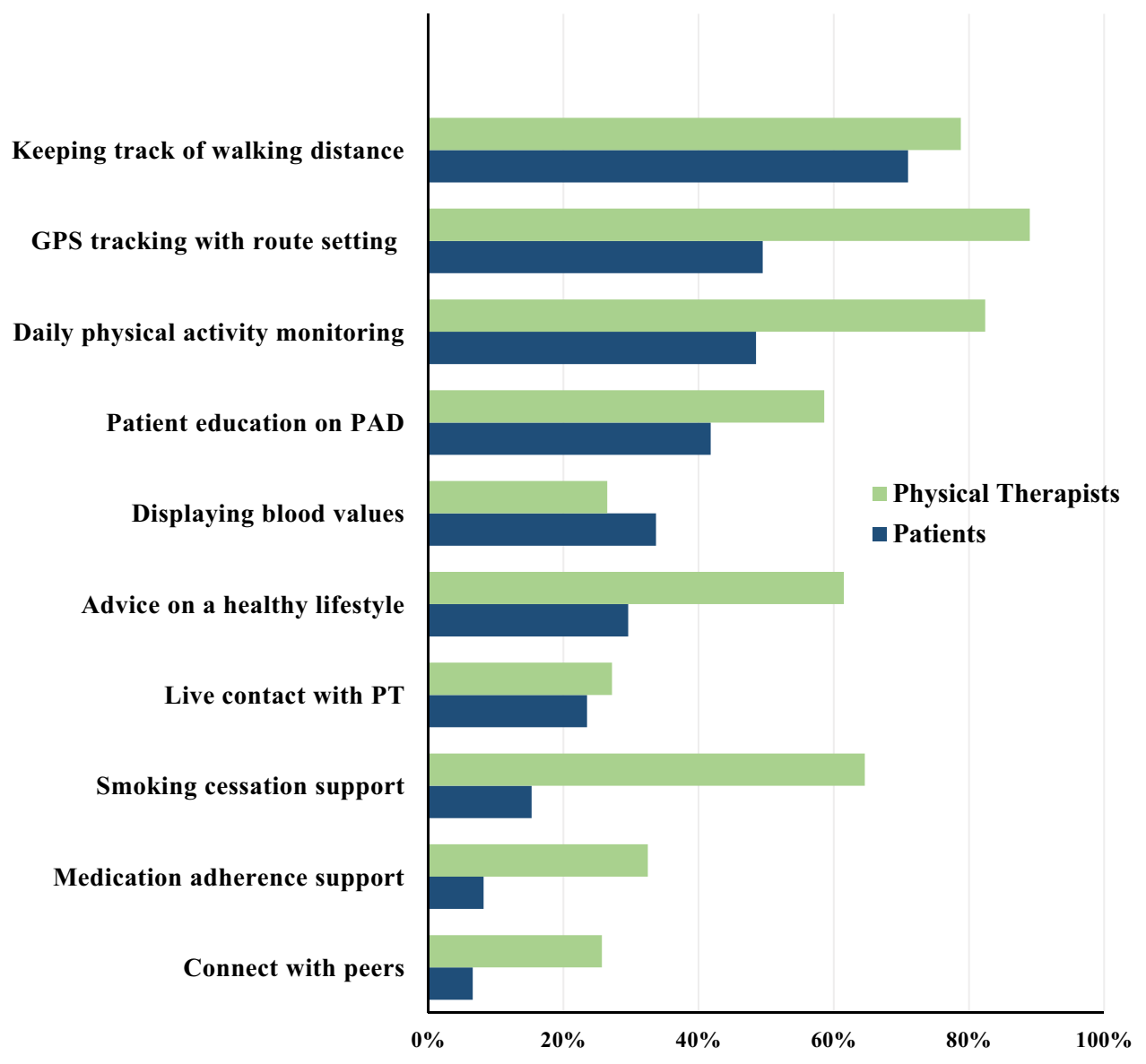

Fig. 2. Preferred smartphone app components of patients $(n=196)$ and physical therapists $(n=584)$ who own a smartphone.

the present study, may increase usability and thereby effectiveness.

Consideration of user preference alone does not guarantee that an mHealth application will be effective. Indeed, Heffner et al. ${ }^{22}$ found that popularity of an app feature does not necessarily go hand-in-hand with effectiveness. For instance, patient education and support with smoking cessation are important treatment goals in SET programs. Likewise, a considerable portion of PTs in our study showed interest in these features. Interestingly, only a small proportion of patients in our study would appreciate information on a healthy lifestyle or help with smoking cessation through an app. Notably, previous mHealth interventions providing smoking cessation support have shown benefits of a magnitude comparable to the effect of interventions such as nicotine replacement therapies. ${ }^{8}$ Evidently, a promising theory or evidence base for a smartphone app is not necessarily met with patients' predilection for using it. Nonetheless, apart from the patients' and clinicians' preferences presented by this survey, developers should heed best practice recommendations backed by evidence or behavioral change theory to potentiate effectiveness.

\section{Strengths and Limitations}

To our knowledge, this is the first study exploring both smartphone ownership and mHealth content preferences of $\mathrm{PAD}$ patients and their treating PTs. A challenge for future research remains to determine if the results of the survey hold true in clinical practice and translate into real-world effectiveness. Several strengths and weaknesses may apply. A large sample was obtained despite a relatively short (1 month) response collection duration. Unfortunately, the number of patients approached by their PT for completion of the questionnaire is unknown. Therefore, an exact patient response rate cannot be determined. A main limitation of the study thereby lies in the uncertainty regarding the validity of extrapolating the results 
to the IC population as a whole. In 2015, a ClaudicatioNet PT saw approximately $2-3$ individual IC patients for at least one treatment session per month (this study's duration). Since 617 PTs responded, they in turn could potentially reach $1,234-1,851$ patients. Thus, with 488 patient respondents, a response rate of $26 \%$ (488/ $1,851)$ to $40 \%(488 / 1,234)$ was possible. Such low response rates are not uncommon for electronic surveys but do warrant careful formulation of the conclusions. ${ }^{12}$

Furthermore, selection bias is a known problem for electronic surveys. We aimed to reduce this risk by presenting the PTs with different modes of administering the questionnaire to their patients, including a printed version. Thus, the survey was not exclusively available for patients with access to the appropriate technology. Nonetheless, it may be possible that PTs only asked patients with a smartphone to complete the survey. The representativeness of the sample may thus be compromised resulting in an overestimation of smartphone penetration rates. To minimize this risk of selection bias, the text that accompanied the survey stated an explicit request to the PTs to include all patients irrespective of smartphone ownership. Furthermore, the questionnaires contained no enquiries on patient characteristics such as medical history, comorbidity, and disease severity (treadmill-measured walking distance and ankle-brachial index). Moreover, IP addresses were not collected so there was no way of checking for duplicates among responding PTs. As the outcome of this survey yields no potential benefit nor detriment for an individual therapist, this risk is probably minimal.

\section{CONCLUSIONS}

A smartphone app aimed at improving health behavior has the potential to reach a substantial proportion of PAD patients. Smartphone ownership is associated with younger age and higher attained educational level; characteristics that carry a relatively favorable cardiovascular risk. Developers and researchers should strive to find solutions for patients without access to the appropriate technology in the design and implementation of mHealth, as this particular subpopulation may be most in need. The current study provides a framework of end-user preferences regarding desired app features and can help guide the development of future mHealth interventions aimed at patients with IC.
The authors would like to acknowledge Loes Hellegers and Yvonne Spierings-Peeters for their support in disseminating the survey via ClaudicatioNet. Furthermore, they would like to thank all respondents of the survey and patients and physical therapists for their contribution.

\section{SUPPLEMENTARY DATA}

Supplementary data related to this article can be found at https://doi.org/10.1016/j.avsg.2017.08. 020.

\section{REFERENCES}

1. Fowkes FG, Rudan D, Rudan I, et al. Comparison of global estimates of prevalence and risk factors for peripheral artery disease in 2000 and 2010: a systematic review and analysis. Lancet 2013;382:1329-40.

2. Society for Vascular Surgery Lower Extremity Guidelines Writing GroupConte MS, Pomposelli FB, Clair DG, et al. Society for vascular surgery practice guidelines for atherosclerotic occlusive disease of the lower extremities: management of asymptomatic disease and claudication. J Vasc Surg 2015;61(3 Suppl):2S-41S.

3. Nicolai SP, Teijink JA, Prins MH, Exercise Therapy in Peripheral Arterial Disease Study Group. Multicenter randomized clinical trial of supervised exercise therapy with or without feedback versus walking advice for intermittent claudication. J Vasc Surg 2010;52:348-55.

4. Burke LE, Ma J, Azar KM, et al. Current science on consumer use of mobile health for cardiovascular disease prevention: a scientific statement from the American Heart Association. Circulation 2015;132:1157-213.

5. Eysenbach G. What is e-health? J Med Internet Res 2001;3: e20.

6. Carter T, O'Neill S, Johns N, et al. Contemporary vascular smartphone medical applications. Ann Vasc Surg 2013;27: 804-9.

7. Fox CS, Hwang SJ, Nieto K, et al. Digital connectedness in the Framingham Heart Study. J Am Heart Assoc 2016;5: e003193.

8. Arsand E, Demiris G. User-centered methods for designing patient-centric self-help tools. Inform Health Soc Care 2008;33:158-69.

9. McCurdie T, Taneva S, Casselman M, et al. mHealth consumer apps: the case for user-centered design. Biomed Instrum Technol 2012;(Suppl):49-56.

10. Merry AH, Teijink JA, Jongert MW, et al. [KNGF-guideline: Symptomatic Intermittent Claudication (author's translation)]. Royal Dutch Society of Physical Therapy (KNGF) 2014. Available at: www.fysionet-evidencebased.nl/index. php/richtlijnen/richtlijnen/symptomatisch-perifeer-arterieelvaatlijden. Accessed October 10, 2017.

11. Lauret GJ, Gijsbers HJ, Hendriks EJ, et al. The ClaudicatioNet concept: design of a national integrated care network providing active and healthy aging for patients with intermittent claudication. Vasc Health Risk Manag 2012;8: 495-503.

12. Hageman D, van den Houten MM, Spruijt S, et al. Supervised exercise therapy: it does work, but how to set up a program? J Cardiovasc Surg (Torino) 2017;58: $305-12$. 
13. Eysenbach G. Improving the quality of web surveys: the checklist for reporting results of internet e-Surveys (CHERRIES). J Med Internet Res 2004;6:e34.

14. Bennett C, Khangura S, Brehaut JC, et al. Reporting guidelines for survey research: an analysis of published guidance and reporting practices. PLoS Med 2010;8:e1001069.

15. Dutch Ministry of Economic Affairs. ICT, Knowledge and Economy. Dutch Central Bureau of Statistics, 2016. pp 87-8. Available at: www.cbs.nl/en-gb/publication/2016/26/ ict-knowledge-and-the-economy-2016-summary/. Accessed October 10, 2017.

16. Albert MA, Glynn RJ, Buring J, et al. Impact of traditional and novel risk factors on the relationship between socioeconomic status and incident cardiovascular events. Circulation 2006;114:2619-26.

17. Eapen ZJ, Peterson ED. Can mobile health applications facilitate meaningful behavior change?:time for answers. JAMA 2015;314:1236-7.
18. Goode AP, Hall KS, Batch BC, et al. The impact of interventions that integrate accelerometers on physical activity and weight loss: a systematic review. Ann Behav Med 2017;51: 79-93.

19. Wang JB, Cataldo JK, Ayala GX, et al. Mobile and wearable device features that matter in promoting physical activity. J Mob Technol Med 2016;5:2-11.

20. Rabin C, Bock B. Desired features of smartphone applications promoting physical activity. Telemed J E Health $2011 ; 17: 801-3$

21. Conway N, Campbell I, Forbes P, et al. mHealth applications for diabetes: user preference and implications for app development. Health Informatics J 2016;22: $1111-20$.

22. Heffner JL, Vilardaga R, Mercer LD, et al. Feature-level analysis of a novel smartphone application for smoking cessation. Am J Drug Alcohol Abuse 2015;41: $68-73$. 